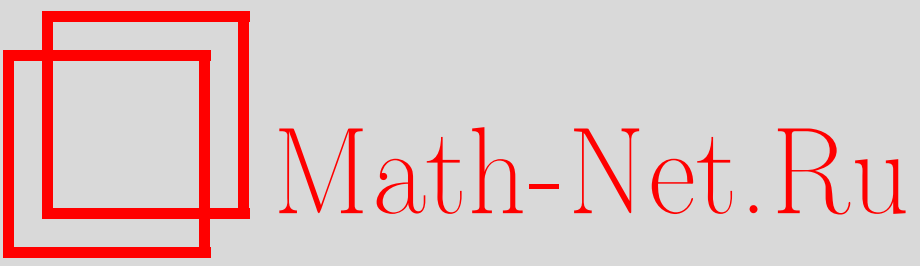

С. А. Дроздовский, В. В. Филиппов, Селекционная теорема для нового класса многозначных отображений, УМН, 1998, том 53, выпуск 5, 235-236

DOI: https://doi.org/10.4213/rm78

Использование Общероссийского математического портала Math-Net.Ru подразумевает, что вы прочитали и согласны с пользовательским соглашением

http://www.mathnet.ru/rus/agreement

Параметры загрузки:

IP: 54.198 .55 .26

26 апреля 2023 г., 12:33:38 


\title{
СЕЛЕКЦИОННАЯ ТЕОРЕМА ДЛЯ НОВОГО КЛАССА МНОГОЗНАЧНЫХ ОТОБРАЖЕНИЙ
}

\author{
С. А. Дроздовский, В. В. Филиппов
}

В данной работе вводится новьй класс многозначных отображений, включающий в себя все полунепрерьвные снизу и полунепрерьвные сверху многозначные отображения, для которого доказьвается селекционная теорема.

Рассматриваемый класс многозначных отображений $\varphi: X \rightarrow \exp Y$ определяется условием

$(*)$ для любой точки $x \in X$ и для любых открытого подмножества $U$ пространства $Y$, содержащего множество $\varphi(x)$, и открытого подмножества $V$ пространства $Y$, пересекающего множество $\varphi(x)$, существует такая окрестность $W$ точки $x$, что для каждой точки $z \in W$ верно хотя бы одно из двух условий:

1) $\varphi(z) \subset U$;

2) $\varphi(z) \cap V \neq \varnothing$.

Основным резулштатом является

Теорема 1. Пусть $X$ - наследственно нормальный паракомпакт, $Y$ - полное метрическое пространство, многозначное отображение $\varphi: X \rightarrow \exp _{c} Y$ удовлетворяет условию (*). Тогда существует полунепрерьвная сверху селекция $\psi: X \rightarrow \exp _{c} Y$ отображения $\varphi$.

Теорема 1 имеет приложения к теории дифференциальных включений, а именно, при рассмотрении дифференциального включения $y^{\prime} \in \varphi(t, y)$, правая часть которого компактнозначна и удовлетворяет условию $(*)$, мы можем перейти к полунепрерьвной сверху селекции $\psi$ отображения $\varphi$. Дифференциальное включение $y^{\prime} \in \psi(t, y)$ удовлетворяет условиям Дэви, и для него существует хорошо разработанная теория задачи Коши, см., например, [2]. В частности, мы имеем теорему существования решения задачи Коши для включения $y^{\prime} \in \psi(t, y)$. Это сразу дает нам теорему существования решения задачи Коши для исходного включения $y^{\prime} \in \varphi(t, y)$.

С другой стороны, в теории дифференциальных включений есть достаточно известные утверждения, где правая часть частью полунепрерьвна сверху, частью полунепрерьвна снизу, см. [3]-[5] Вводимый класс многозначных отображений может оказаться удобньм инструментом в исследовании таких ситуаций, являясь здесь максимально широким.

Необходимость требования наследственной нормалшности пространства $X$ в теореме 1 показывает следующее утверждение.

Tеорема 2. Пусть $X-T_{1}$-пространство, $Y=\{0 ; 1\}$ - дискретное двоеточие. Если любое многозначное отображение из $X$ в $\exp Y$ со свойством (*) имеет полунепрерывную сверху селекцию, то пространство $X$ наследственно нормально.

Изложим кратко схему доказательства теоремы 1.

Тихоновское пространство $X$ имеет абсолют $A(X)$, которьй экстремально несвязен. Соответствующее отображение $\pi_{X}: A(X) \rightarrow X$ совершенно. Так как $X$ - паракомпакт, $A(X)$ тоже является паракомпактом.

Вследствие наследственной нормальности $X$ и экстремальной несвязности $A(X)$ в каждой точке $x \in A(X)$ множество $\theta(x)=\liminf _{y \rightarrow x} \varphi \pi_{X}(y)$ непусто, и селекция $\theta: A(X) \rightarrow \exp _{c} Y$ отображения $\varphi \pi_{X}$ полунепрерьвна снизу.

Согласно компактнозначной теореме Майкла о селекциях [1], существует полунепрерьвная сверху компактнозначная селекция $\eta$ отображения $\theta$. Отображение $\psi=\eta \pi_{X}^{-1}$ компактнозначно и является полунепрерьвной сверху селекцией для $\varphi$.

Работа выполнена при финансовой поддержке Российского фонда фундаментальных исследований (грант № 98-01-00061). 
СлеДСтвИЕ 1. Пусть $X$ - наследственно нормальный паракомпакт, $X_{0}-$ его замкнутое подмно сество, $Y$ - полное метрическое пространство, многозначное отображсние $\varphi: X \rightarrow \exp _{c} Y$ полунепрерывно снизу. Тогда всякая полунепрерывная сверху селекция $\psi: X_{0} \rightarrow \exp _{c} Y$ отображения $\left.\varphi\right|_{X_{0}}$ продолжается на все $X$ до полунепрерывной сверху компактнозначной селекиии отображения $\varphi$.

СЛЕДСТВИЕ 2. Если в условиях следствия 1 отказаться от замкнутости множества $X_{0}$, но предположить дополнительно локальную компактность пространства $Y$ и непрерывность отображения $\varphi$, то утверждение следствия 1 останется в силе.

\section{СПИСОК ЛИТЕРАТУРЫ}

[1] Michael E. // Duke Math. J. 1959. V. 26. Р. 647-652. [2] Филиппов В. В. Пространства решений обыкновенных дифференциальных уравнений. М.: Изд-во МГУ, 1993. [3] Averna D., Marano S. A. // Rend. Sem. Mat. Univ. Padova.. [4] Bressan A. // Pure Appl. Math. 1990. V. 133. P. 21-31. [5] Lojasiewicz S. // Banach Center Publ. 1985. V. 14. P. 625-643.

Московский государственньй

университет им. М.В. Ломоносова
Принято редколлегией 01.04.1998 